ИЗВЕСТИЯ АКАДЕМИИ НАУК ЭСТОНСКОИ ССР. ТОМ 32 ГЕОЛОГИЯ, 1983, № 1

\title{
ИЗМЕРЕНИЯ СИЛЫ ПРИТЯЖЕНИЯ 17-ЭТАЖНОГО ЗДАНИЯ
}

Настоящая работа проведена с целью проверки возможности использования формулы Буге (Мельхиор, 1975) для определения силы притяжения параллельных друг другу плоскостей, вызывающих гравитационную аномалию, при решении некоторых теоретических и практических задач.

Объектом исследования был выбран 17-этажный дом, так как масса этого здания известна и на этажах удобно измерять силу притяжения. Межэтажные перекрытия рассматривались как параллельные друг другу плоскости, которые своей массой вызывают гравитационное притяжение. Расчетные величины силы притяжения сравнивали с измеренными.

Измерения силы притяжения 17-этажного здания общей массой $11386 \cdot 10^{9}$ г проводили гравиметром типа ГрК2. Измерения внутри здания проводили на $1,5,9,13,17$-м этажах, на крыше и в четырех точках вокруг здания. Внутри здания проводили 3 серии измерений, а вне его 2 серии. Здание имеет кирпичные стены, железобетонные перекрытия и свайные фундаменты. Плановое решение здания овальное, симметричное, ширина его 21, длина 32 , общая высота 51,55 и высота этажа 2,80 м. Местность в районе измерений ровная и характеризуется постоянством геологического разреза.

Термином «сила притяжения» в данной работе обозначается вертикальный компонент силы притяжения, действующий на единичную массу.

Наблюдения $\Delta g$ проводили гравиметром ГрК2 при благоприятных метеорологических условиях. Погода была хорошая, ветер слабый, микросейсмический фон отсутствовал. При наблюдениях не было отмечено собственного колебания здания. Среднеквадратичная погрешность измерений не превышала $\pm 0,02$ мГал. Внутри здания по вертикальной оси симметрии измерялось суммарное значение силы притяжения Земли и здания.

Чтобы найти силу притяжения здания, для этого от общей силы притяжения высчитывали величину тяготения Земли в условиях свободного воздуха. Сила притяжения Земли в условиях свободного воздуха определялась с помощью градиента, который вычисляли между пунктами вокруг здания и пунктом на 9-м этаже. Было принято, что в середине здания на 9-м этаже сила притяжения здания близка нулю, поскольку силы притяжения нижней и верхней частей здания почти уравновешиваются. При этом из величины силы притяжения на этажах высчитывали силу притяжения крыши, так как они не уравновешиваются.

Точки измерения вокруг здания выбирались на расстоянии 90 м от него, так как вертикальный компонент силы притяжения здания там меньше чувствительности гравиметра $(<0,01$ мГал).

На малой высоте над уровнем моря вертикальный градиент силы тяжести на наших широтах приблизительно равен 0,3086 мГал/м.

По данным измерения градиент силы притяжения Земли в условиях свободного воздуха 0,3057 мГал/м. Масса здания уменьшает градиент силы притяжения Земли, и поэтому средний градиент силы притяжения Земли внутри здания 0,2978 мГал/м. 
Центр массы здания находится на 0,30 м ниже 9-го этажа, а не в середине здания, как раньше предполагалось. Это объясняется тем, что толщина стен в нижней половине здания 51 , а в верхней части 38 см.

Поправки за изменения температуры не учитывались, так как гравиметр ГрК2 имел систему температурного компенсатора и, кроме того, здание не отапливалось, оконные проемы не были застеклены, температура внутри здания практически не отличалась от наружной.

Поправка за высоту $\Delta F_{H}$ вычислялась по формуле (Мельхиор, 1975)

$$
\Delta F=\omega^{2} \cdot \cos ^{2} \Phi \cdot \Delta H,
$$

где $\omega-$ угловая скорость вращения Земли;

Ф - географическая широта;

$\Delta H$ - разница высот.

Все измеренные силы притяжения относительные. За ноль принималась величина силы притяжения в середине здания на 9-м этаже.

Перед измерениями были проведены ориентировочные расчеты для определения силы притяжения здания, чтобы убедиться в возможности проведения измерений в пределах чувствительности гравиметра ГрК2. Метод расчета основывался на формуле Буге (Мельхиор, 1975) с той лишь разницей, что радиус диска принимался не $R=\infty$, а $R=R$ ред.

$$
F=2 \pi G \mu\left(1-\frac{1}{\sqrt{1+\frac{R^{2}}{h^{2}}}}\right)
$$

где $F-$ сила притяжения, действующая на единичную массу;

$G$ - гравитащионная постоянная;

$\mu$ - поверхностная плотность (плотность простого слоя);

$R$ - радиус диска;

$h$ - расстояние между плоскостью и точкой измерения.

$R_{\text {ред. }}$ (редуцированный) - радиус круга такой площади, который численно равняется площади этажа. Площадь этажа равна $S=587,52$ м $^{2}$.

Считалось, что масса этажа сконцентрирована в плоскости этажа. Из такого предположения вытекает, что поверхностная плотность этажа $\mu=119 \mathrm{r} / \mathrm{cm}^{2}$ для нижней половины здания и $\mu=109 \mathrm{r} / \mathrm{cm}^{2}$ для верхней половины. Расстояние между плоскостью и точкой измерения принималось кратным высоте этажа

$$
h=2,80 n,
$$

где $n$ (число этажей) $=1 \ldots 16$.

Сила притяжения здания на конкретном этаже определяется суммой сил притяжений всех остальных этажей. Рассчитанная таким способом сила притяжения здания, как и предполагалось, хорошо совпадает с измеренной. Результаты измерений и расчетов приведены в таблице и на рис. 1,2 . Как видно из рис. 1 , где приведены график суммарной силы притяжения Земли и здания и график силы притяжения здания, расчетные и измеренные данные хорошо совпадают. Масштаб силы притяжения здания увеличен в десять раз с целью улучшения выразительности графика.

Отрицательные величины силы притяжения (таблица, рис. 1) обозначают не отталкивающие силы, а показывают то, что они измерялись относительно. Как уже было сказано, сила притяжения на 9-м этаже принята за ноль. Все силы притяжения, превосходящие силу притяжения на 9-м этаже, обозначены знаком плюс, все силы притяжения, которые меньше, чем сила притяжения на 9-м этаже, обозначены знаком минус. 


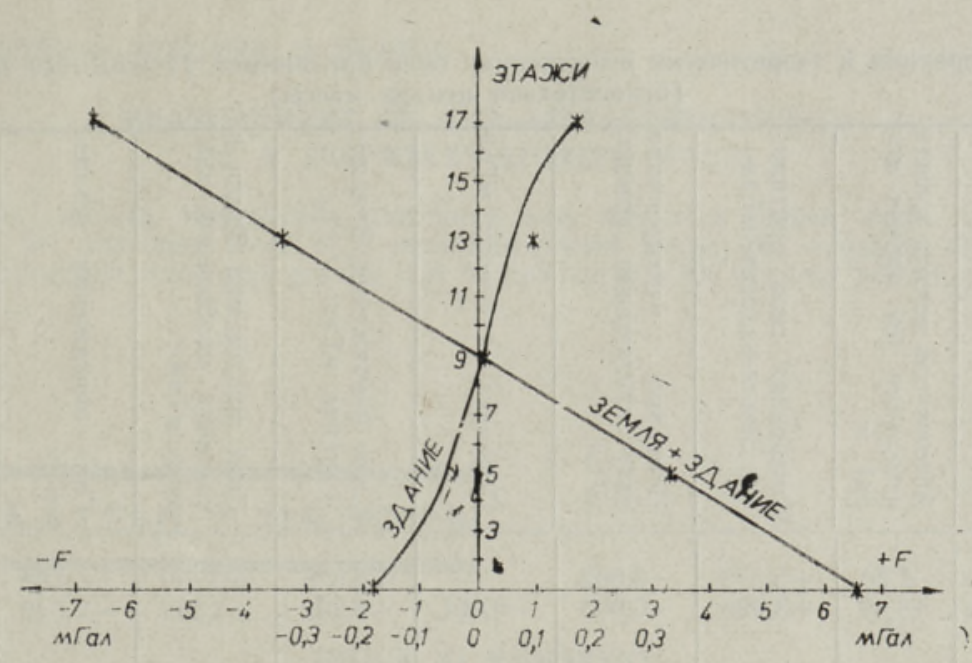

Рис. 1. Графики измеренных и расчетных сил притяжений. Звездочкой отмечена измеренная сила притяжения.

График градиентов силы притяжения здания (рис. 2) построен на основе расчетных значений силы притяжения здания, поскольку на основе измерений подробный график построить невозможно.

О направлении силы притяжения можно судить на основе градиента силы притяжения здания (рис. 2). Положительные значения градиента отмечают силу, направленную в сторону Земли, отрицательные - от Земли. Нулевое значение градиента силы притяжения соответствует равновесию сил.

Анализ теоретических данных и результатов измерений показывает, что формулу Буге можно использовать для расчета силы притяжения параллельных дискообразных плоскостей. Принятые упрощения - сконцентрированная масса этажа в плоскости этажа, применение $R$ ред. значительно уменьшают объем расчетов, причем расчетные и измеренные силы притяжения здания почти совпадают.

Для первого этажа различие между расчетными и измеренными величинами силы притяжения здания равно 0,002 мГал, что составляет $1 \%$ от максимальной силы притяжения здания. Для пятого этажа это различие составляет 0,016 мГал, или $9 \%$, на девятом 0,004 мГал, или $2 \%$, на тринадцатом этаже 0,032 мГал, или $18 \%$, на семнадцатом этаже различий не отмечено (см. таблицу).

Методики для расчета силы притяжения здания нет. Авторам данной статьи так и не удалось выяснить, проводились ранее аналогичные измерения силы притяжения здания или нет.

На основе изложенных измерений и расчетов силы притяжения здания можно сделать следующие выводы.

1. Для измерения силы притяжения массивного здания можно использовать наземные узкодиапазонные кварцевые гравиметры первого или второго класса.

2. Силы притяжения здания можно рассчитать с точностью, соответствующей всем

Púc. 2. Графики градиентов сил притяжений.

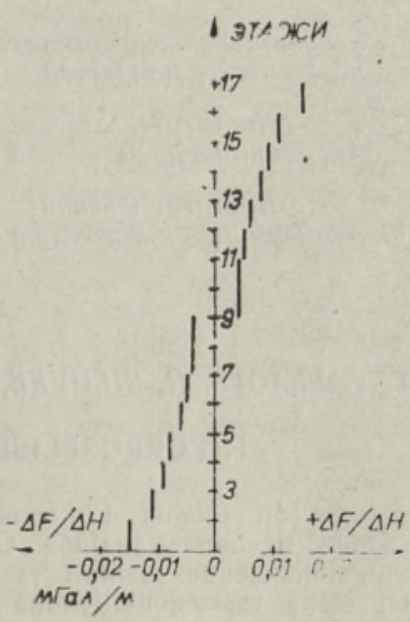


Измеренная и теоретически вычисленная сила притяжения 17-этажного здания (относительно центра массы)

\begin{tabular}{|c|c|c|c|c|c|c|c|c|}
\hline 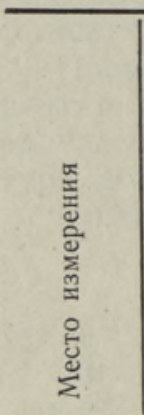 & 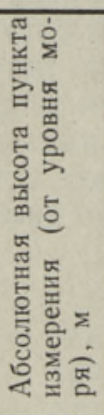 & 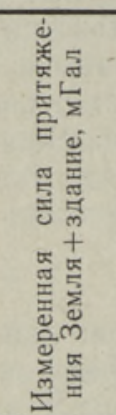 & 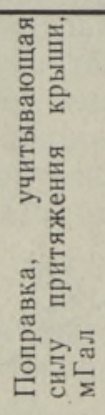 & 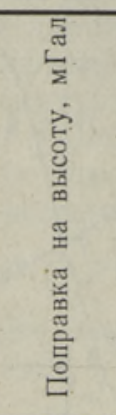 & 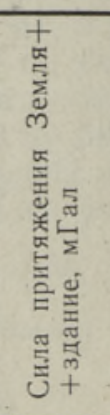 & 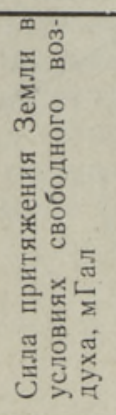 & 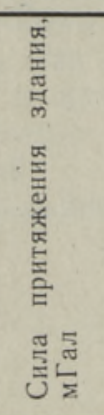 & 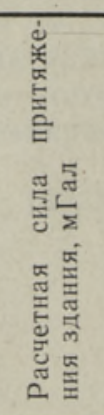 \\
\hline $\begin{array}{c}1 \text {-й } \\
5 \text {-й } \\
\text { этаж }\end{array}$ & $\begin{array}{r}7,20 \\
18,40\end{array}$ & $\begin{array}{l}+6,578 \\
+3,296\end{array}$ & $\begin{array}{l}-0,002 \\
-0,003\end{array}$ & $-0, \overline{001}$ & $\begin{array}{l}+6,576 \\
+3,292\end{array}$ & $\begin{array}{l}+6,756 \\
+3,332\end{array}$ & $\begin{array}{l}-0,180 \\
-0,040\end{array}$ & $\begin{array}{l}-0,182 \\
-0,056\end{array}$ \\
\hline $\begin{array}{l}\text { Центр } \\
\text { массы } \\
\text { здания } \\
9 \text {-й этаж } \\
13 \text {-й этаж } \\
17 \text {-й этаж }\end{array}$ & $\begin{array}{l}29,30 \\
29,60 \\
40,80 \\
52,00\end{array}$ & $\begin{array}{c}0 \\
-3,406 \\
-6,727\end{array}$ & $\begin{array}{l}-0,006 \\
-0,012 \\
-0,034\end{array}$ & $\begin{array}{l}-0,003 \\
-0,005 \\
-0,006\end{array}$ & $\begin{array}{c}0 \\
-0,009 \\
-3,423 \\
-6,767\end{array}$ & $\begin{array}{c}0 \\
-0,009 \\
-3,516 \\
-6,939\end{array}$ & $\begin{array}{c}0 \\
+0,009 \\
+0,093 \\
+0,172\end{array}$ & $\begin{array}{l}+\overline{013} \\
+0,013 \\
+0,061 \\
+0,172\end{array}$ \\
\hline $\begin{array}{l}\text { Поверх- } \\
\text { ность } \\
\text { земли }\end{array}$ & 6,07 & $+7,186$ & - & - & $+7,186$ & & & \\
\hline
\end{tabular}

практическим требованиям, пользуясь методикой, приведенной в данной статье.

3. Зная значение силы тяжести на первом этаже можно подобным образом вычислить силу тяжести на других этажах с точностью $\pm 0,02-$ 0,03 мГал. При этом необходимо учитывать, что сила притяжения здания снижает градиент силы притяжения Земли.

4. При геологической интерпретации гравитационных аномалий по приведенной методике можно рассчитать притяжение горизонтально залегающих пластин с одинаковыми или разными толщинами и плотностями.

\section{Л И Т Е Р А Т У Р А}

Мельхиор П. Физика и динамика планет. М., 1975.
Государственный комитет Эстонской ССР по делам строительства - Госстрой
Поступила в редакцию 28/I 1982

Ннститут геологии

Академии наук Эстонской ССР

Ннститут физики

Академии наук Эстонской ССР

T. VALLAOTS, H. SILDVEE, R. PREEM

\section{7-KORRUSELISE HOONE KOLGETOMBEJOU MOOTMINE}

Artiklis on toodud 17-korruselise hoone külgetõmbejõu arvutatud ja mõõtmise teel saadud tulemuste analüüs. On esitatud metoodika, mille abil saab arvutada hoonete külgetõmbejõudu, samuti raskusjõukiirendust hoone eri korrustel (viimast juhul, kui on teada raskusjõukiirendus 1. korrusel) praktilisteks otstarveteks piisava täpsusega. 


\section{MEASUREMENT OF THE ATTRACTION FORCE OF A SEVENTEEN-STORIED HOUSE}

The article contains theoretically calculated and measured values (with a gravity meter) of the attraction force of a seventeen-storied house. The equation shows that both the attraction force and gravity can be calculated with required precision for any storey.

\section{INQUA XI KONGRESS}

1.-9. augustini 1982 toimus Moskvas Rahvusvahelise Kvaternaari Uurimise Liidu (INQUA) XI kongress, milles osales üle 1000 teadlase 62 riigist, sealhulgas 13liikmeline delegatsioon Eesti NSV-st. Kongressi avas organiseerimiskomitee esimees, NSVL TA Geoloogia, Geofüüsika ja Geokeemia Osakonna akadeemiksekretär B. Sokolov. Tervitajate hulgas oli UNESCO Maa Teaduste Osakonna direktor V. Sibrava (Tšehhoslovakkia) ja teisi nimekaid teadlasi. Kuigi liidu I kongress toimus juba 1928. aastal Kopenhaagenis, oli käesolev tegelikult juubelikongress, sest alles 1932, aastal Leningradis peetud II kongressil võeti vastu otsus rahvusvahelise liidu moodustamise kohta (varem nimetati seda Euroopa assotsiatsiooniks). Et 1982. aasta läks ajalukku ka Nõukogudemaa geoloogiateenistuse juubeliaastana (1882 moodustati Venemaa Geoloogiakomitee), siis oli INQUA XI kongress seda pidulikum. Oks istung oligi kuulutatud juubeliistungiks, kus geoloogia-mineraloogiadoktor I. Krasnov meenutas II kongressil toimunut.

INQUA ühendab väga paljude teadusharude esindajaid - geolooge, geograafe, biolooge, arheolooge, füüsikuid, keemikuid jt., kôiki, kes uurivad viimase kahe aastamiljoni vältel asetleidnud looduslikke protsesse. Kuivõrd inimtegevus (maaharimine, tööstus- ja tsiviilehitus jne.) toimub suuremalt jaolt kvaternaari setetel, siis on kvaternaariajastu uurimisel väga suur rakenduslik tähendus. Liidu ülesannete hulka kuulub ka inimkonda puudutavate looduslike sündmuste (Maa kliima lähitulevikus, muutused rannajoones jms.) prognoosimine. Eriti suurt huvi ja diskussiooni tekitas USA ja Nöukogude Liidu teadlaste ühistöö viljana valminud kliima prognoosimise mudel. Elavalt arutleti kvaternaariajastu alumise piiri, ookeaninōgude kujunemise ja arengu, maavärinate ja vulkaanipursete ennustamise, ahvinimeste ja ürginimeste evolutsiooni ning keskkonnakaitse ümber. Vaatluse all olid

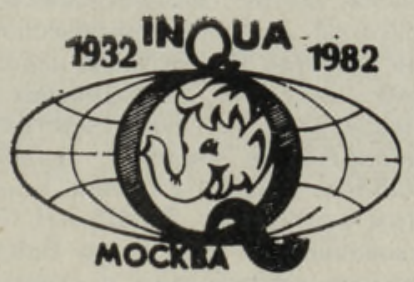

ka mõnede teiste taevakehade ehitus ja kliima, ehitusgeoloogia, kvaternaari maavarade ratsionaalne kasutamine. Kokku kuulati 24 sektsioonis ja 6 sümpoosionil ligikaudu 1100 . ettekannet, neist 9 meie koduvabariigi uurijatelt. Sõnavōtjad pidasid eriti vajalikuks uurimismeetodite edasiarendamist ja ühtlustamist, sealhulgas distantsuurimise täiustamist. Konstateeriti uurimistöö tōsist mahajäämust Aafrika, Aasia ja Lõuna-Ameerika riikides.

Kongressil valiti liidu uus täitevkomitee ja kinnitati komisjonide juhtkonnad. Uueks presidendiks valiti silmapaistev prantsuse teadlane prof. H. Faure ja peasekretäriks šveitslane Chr. Schlüchter. Oheks asepresidendiks sai Nőukogude teadlane $M$. Aleksejev. Komisjonide juhtkondades on Nõukogude Liidu esindajaid varasemast tagasihoidlikumalt. Paleogeograafiliste atlaste komisjoni presidendiks kinnitati geograafiadoktor A. Velitško, setete geneesi ja litoloogia komisjoni asepresidendiks geoloogia-mineraloogiadoktor A. Raukas, rannajoonte komisjoni asepresidendiks geograafiadoktor P. Kaplin ning stratigraafiakomisjoni asepresidendiks geoloogia-mineraloogiadoktor M. Aleksejev. Auliikmeiks valitute hulgas on nôukogude teadlased akadeemik I. Gerassimov, akadeemik G. Goretski ja prof. K. Nikiforova. INQUA uuteks liikmesriikideks võeti vastu Alžeeria, Hiina RV, Kreeka ja Portugal. Järgmine kongress otsustati pidada 1987. aastal Kanadas.

A. RAUKAS 